\title{
Influence of rotational speed on the statistical variability of heat penetration parameters and on the non-uniformity of lethality in retort processing
}

\author{
C. Smout ${ }^{a}$, I. Ávila ${ }^{b}$, A.M.L. Van Loey ${ }^{a}$, M.E.G. Hendrickx ${ }^{a, *}$, C. Silva ${ }^{b}$ \\ a Laboratory of Food Technology, Department of Food and Microbial Technology, Faculty of Agricultural and Applied Biological Sciences, Katholieke \\ Universiteit Leuven, Kardinaal Mercierlaan 92, B-3001 Heverlee, Belgium \\ ${ }^{\mathrm{b}}$ Escola Superior de Biotecnologia, Universidade Católica Portuguesa, Rua Dr. António Bernardino de Almeida, P-4200 Porto, Portugal
}

\begin{abstract}
Keywords: Heat penetration; Non-uniformity; Lethality; Retort; Rotation

In a case study on white beans, the effect of rotation on the statistical variability of heat penetration parameters and on the nonuniformity of lethality in industrial-scale retort processing was investigated. In addition, the influence of process time on the nonuniformity of lethality was evaluated. No clear relation between the non-uniformity of the heating parameters and the rotational speed was observed. Rotation seemed to influence process lethality variability throughout the retort by its effect on non-uniformity in heating characteristics and in retort temperature. Absolute non-uniformity (i.e. standard deviation) increased with increasing holding time, whereas relative non-uniformity (i.e. coefficient of variation) decreased as holding time increases.
\end{abstract}

\section{Introduction}

Thermal processing of foods is one of the most important preservation techniques in the food industry to extend the shelf-life of foods. It generally involves heating of foods for a predetermined time at a preselected temperature to eliminate pathogenic microorganisms that endanger the public health as well as those microorganisms and enzymes that deteriorate the food during storage. Today, the consumer demands more than the production of safe and shelf-stable foods and insists on high-quality foods. The more severe the thermal process, the greater will be the degradation of food quality, both in sensorial (color, flavor, texture) and nutritional factors.

Rotational processes may be applied to liquid or semi-fluid foods to increase heat flow rates by forced convection within the container (Berry, Savage \& Pflug,

\footnotetext{
${ }^{*}$ Corresponding author. Tel.: +32-16-321585; fax: +32-16-321960.

E-mail address: marc.hendrickx@agr.kuleuven.ac.be (M.E.G. Hendrickx).
}

1979; Naveh \& Kopelman, 1980; Van Loey et al., 1994). Assuming there is adequate heat supply, this can lead to shorter process times with improved sensorial quality and reduced nutrient losses. However, processing in rotary retort systems involves complex heat transfer mechanisms. Therefore, process time needs to be carefully controlled since heating rates are known to be influenced by several variables such as rotational speed, container location with respect to radius and angle of rotation, mode of rotation (end-over-end or axially), headspace, product viscosity and degree of overpressure (Clifcorn, Peterson, Boyd \& O'Neil, 1950; Berry et al., 1979; Berry \& Bradshaw, 1980; Naveh \& Kopelman, 1980; Berry \& Dickerson, 1981; Javier, Naveh, Perlstein \& Kopelman, 1985; Tung \& Britt, 1992; Abbatemarco \& Ramaswamy, 1993; Ramaswamy, Abbatemarco \& Sablani, 1993).

Reduction of excessive safety margins used in industry and consequent reduction of quality loss and costs are only possible with a complete statistical study on heat penetration parameters and lethality variability.

The objective of this study was to evaluate the effect of rotation on the statistical variability of heat 
Table 1

Processing conditions heat penetration experiments

\begin{tabular}{lcll}
\hline & $\begin{array}{c}\text { Time } \\
(\mathrm{min})\end{array}$ & $\begin{array}{l}\text { Temperature } \\
\left({ }^{\circ} \mathrm{C}\right)\end{array}$ & $\begin{array}{l}\text { Pressure } \\
(\text { bar })\end{array}$ \\
\hline Come up & 8 & $40-121$ & $0.5-2.0$ \\
Holding & 20 & 121 & 2.0 \\
Cooling & 5 & $121-90$ & $2.0-1.6$ \\
Cooling & 7 & $90-35$ & $1.6-0.5$ \\
Forced cooling & 20 & - & $0.5-0.0$ \\
\hline
\end{tabular}

penetration parameters and on the non-uniformity of lethality in industrial-scale retort processing. Also the influence of process time on the non-uniformity of lethality was investigated. For this research, a case study on white beans was selected.

\section{Materials and methods}

\subsection{Statistical variability heat penetration parameters}

\subsubsection{Product}

Two different lots of dry white beans were used: lot A $(15.14 \pm 1.30 \mathrm{~mm}$ length, $10.58 \pm 0.80 \mathrm{~mm}$ width and $8.71 \pm 0.80 \mathrm{~mm}$ thickness) and lot B (8.86 $\pm 0.50 \mathrm{~mm}$ length, $5.98 \pm 0.37 \mathrm{~mm}$ width and $5.30 \pm 0.51 \mathrm{~mm}$ thickness). The dry beans (stored dry at $15^{\circ} \mathrm{C}$ ) were soaked for at least $16 \mathrm{~h}$ in distilled and demineralized water at $15^{\circ} \mathrm{C}$. Analysis of the soaking behavior of the white beans proved that beans of both lots reached their maximal moisture content after $16 \mathrm{~h}$. Containers $(370 \mathrm{ml}$ glass jars, depth between cover and bottom is $95 \mathrm{~mm}$, diameter is $80 \mathrm{~mm}$ ) were hand-filled with $240( \pm 1) \mathrm{g}$ soaked white beans and covered with distilled and demineralized water until a headspace of $10 \mathrm{~mm}$ was left. Preliminary heat penetration tests were performed to determine the coldest spot within the container. In the static mode, the coldest spot of the product was detected at $15 \mathrm{~mm}$ from the bottom of the jar, along the central axis. For the rotary condition, analysis of variance showed no significant difference among the $F_{0}$ - and $f_{\mathrm{h}}$ values obtained at the different positions. As no significant difference $(P>0.05)$ could be found, the same position as in the static condition, which is at $15 \mathrm{~mm}$ from the bottom, was selected as position for further heat penetration runs in rotary mode.

For lot A the statistical variability of the heating parameters was investigated at 0 and $7 \mathrm{rpm}$, whereas for lot $\mathrm{B}$ the statistical variability of the heating parameters was studied at $0,4,7,10$ and $15 \mathrm{rpm}$. For each condition, at least 100 containers were processed. For the experiment in the static mode, the jars were processed in 5 runs. In the rotary mode, the jars were processed in 10 runs.

\subsubsection{Retort system}

The containers have been processed (in different runs) in a pilot 1-basket water cascading rotary retort (Barriquand Steriflow retort, France). The retort can operate in static or rotational mode. The dimensions of the basket are $0.40 \times 0.37 \times 0.70 \mathrm{~m}^{3}$ (width $\times$ height $\times$ depth), whereas in industrial-scale retort systems the dimensions of a basket are $0.80 \times 0.80 \times 0.85 \mathrm{~m}^{3}$ (width $\times$ height $\times$ depth). As a consequence, statistical variability of heat penetration parameters in industrial-scale retort systems could be higher.

\subsubsection{Datalogging equipment}

The Ellab CMC-92 data acquisition system (Ellab, Denmark) was used to register temperature histories in the pilot retort. A multiplexer box (UMX6-88) was connected to a personal computer and installed with two thermocouple boxes (TR9216), each containing a reference junction and 16 temperature measurement channels. Output had an accuracy of $\pm 0.1^{\circ} \mathrm{C}$.

Thermocouples were copper-constantan (type T) from Ellab (Denmark).

Needle-type thermocouple probes with rounded tip (SSA-12XXX-G700-SF, with XXX the length of the needle in $\mathrm{mm}$, and SSA-12080-G700-TF) were used to measure temperatures at the coldest spot of the product. Space bars were used to be able to measure at the desired position in the product. Two thermocouple probes (SSR-60020-G700-SF, $20 \times 6 \mathrm{~mm}^{2}$ for liquids and air) were placed among the containers to monitor the processing medium temperature.

Thermocouples were calibrated in an oil bath at $90^{\circ} \mathrm{C}$ against a quartz-thermometer (testo 781, Testoterm,
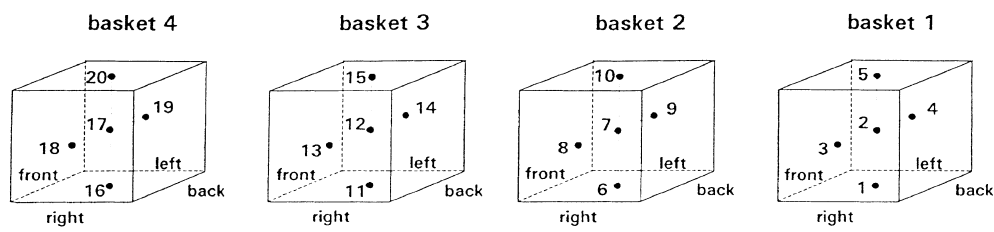

Fig. 1. Thermocouple layout for temperature distribution test throughout the industrial-scale water cascading retort. Side-view of positioning of baskets in the retort. 
Table 2

Estimates of means $(\bar{X})$ and standard deviations $(s)$, coefficients of variation $(\mathrm{CV})$ and normality test $(\operatorname{Pr}<W)$ of the experimentally determined heat penetration parameters

\begin{tabular}{|c|c|c|c|c|c|}
\hline & Parameter & $\bar{X}$ & $s$ & CV $(\%)$ & Normality $\operatorname{Pr}<W$ \\
\hline White beans & $f_{\mathrm{h}}(\min )$ & 10.01 & 0.3 & 3.0 & 0.91 \\
\hline Lot A & $j_{\mathrm{h}}$ & 3.16 & 0.19 & 6.1 & 0.51 \\
\hline \multirow[t]{3}{*}{$0 \mathrm{rpm}$} & $j_{\mathrm{hB}}$ & 0.94 & 0.03 & 3.0 & 0.24 \\
\hline & $\operatorname{adj} . f_{\mathrm{h}}(\min )$ & 8.99 & 0.4 & 4.5 & 0.25 \\
\hline & adj. $j_{\mathrm{h}}$ & 1.17 & 0.05 & 4.5 & 0.20 \\
\hline White beans & $f_{\mathrm{h}}(\min )$ & 7.73 & 0.44 & 5.7 & 0.28 \\
\hline Lot A & $j_{\mathrm{h}}$ & 4.78 & 0.77 & 16.2 & 0.0009 \\
\hline \multirow[t]{3}{*}{$7 \mathrm{rpm}$} & $j_{\mathrm{hB}}$ & 1.05 & 0.08 & 7.5 & 0.009 \\
\hline & $\operatorname{adj} . f_{\mathrm{h}}(\min )$ & 7.46 & 0.38 & 5.1 & 0.04 \\
\hline & adj. $j_{\mathrm{h}}$ & 1.12 & 0.07 & 6.2 & 0.76 \\
\hline White beans & $f_{\mathrm{h}}(\min )$ & 9.74 & 1.00 & 10.2 & 0.04 \\
\hline Lot B & $j_{\mathrm{h}}$ & 3.44 & 0.98 & 28.5 & 0.0001 \\
\hline \multirow[t]{3}{*}{$0 \mathrm{rpm}$} & $j_{\mathrm{hB}}$ & 1.03 & 0.14 & 13.5 & 0.0001 \\
\hline & $\operatorname{adj} . f_{\mathrm{h}}(\min )$ & 9.09 & 0.87 & 9.6 & 0.0001 \\
\hline & $\operatorname{adj} . j_{\mathrm{h}}$ & 1.09 & 0.1 & 9.2 & 0.003 \\
\hline White beans & $f_{\mathrm{h}}(\min )$ & 8.88 & 0.57 & 6.5 & 0.02 \\
\hline Lot B & $j_{\mathrm{h}}$ & 3.34 & 0.59 & 17.6 & 0.0001 \\
\hline \multirow[t]{3}{*}{$4 \mathrm{rpm}$} & & 0.90 & 0.07 & 8.3 & 0.0001 \\
\hline & $\operatorname{adj} . f_{\mathrm{h}}(\min )$ & 7.93 & 0.64 & 8.0 & 0.70 \\
\hline & $\operatorname{adj} . j_{\mathrm{h}}$ & 1.1 & 0.1 & 9.4 & 0.004 \\
\hline White beans & $f_{\mathrm{h}}(\min )$ & 7.49 & 0.42 & 5.6 & 0.68 \\
\hline Lot B & $j_{\mathrm{h}}$ & 4.79 & 0.74 & 15.5 & 0.0001 \\
\hline \multirow[t]{3}{*}{$7 \mathrm{rpm}$} & $j_{\mathrm{hB}}$ & 1.03 & 0.07 & 6.5 & 0.15 \\
\hline & $\operatorname{adj} . f_{\mathrm{h}}(\min )$ & 7.2 & 0.59 & 8.1 & 0.52 \\
\hline & $\operatorname{adj} . j_{\mathrm{h}}$ & 1.12 & 0.1 & 9.0 & 0.51 \\
\hline White beans & $f_{\mathrm{h}}(\min )$ & 6.59 & 0.59 & 8.9 & 0.52 \\
\hline Lot B & $j_{\mathrm{h}}$ & 6.95 & 2.18 & 31.4 & 0.0001 \\
\hline \multirow[t]{3}{*}{$10 \mathrm{rpm}$} & $j_{\mathrm{hB}}$ & 1.17 & 0.17 & 14.5 & 0.0001 \\
\hline & $\operatorname{adj} . f_{\mathrm{h}}(\min )$ & 6.47 & 0.75 & 11.5 & 0.04 \\
\hline & adj. $j_{\mathrm{h}}$ & 1.17 & 0.14 & 11.8 & 0.16 \\
\hline White beans & $f_{\mathrm{h}}(\min )$ & 5.94 & 0.68 & 11.4 & 0.0001 \\
\hline Lot B & $j_{\mathrm{h}}$ & 8.22 & 2.63 & 32.0 & 0.05 \\
\hline \multirow[t]{3}{*}{$15 \mathrm{rpm}$} & $j_{\mathrm{hB}}$ & 1.11 & 0.14 & 12.7 & 0.42 \\
\hline & $\operatorname{adj} . f_{\mathrm{h}}(\min )$ & 5.62 & 0.71 & 12.7 & 0.04 \\
\hline & adj. $j_{\mathrm{h}}$ & 1.13 & 0.13 & 11.6 & 0.49 \\
\hline
\end{tabular}

Belgium; resolution is $0.001^{\circ} \mathrm{C}$ and accuracy $= \pm 0.1^{\circ} \mathrm{C}$ ) and were mutually compared in the pilot retort at the processing temperature $\left(121^{\circ} \mathrm{C}\right)$.

A 32-channel slipring contact (Ecklund, USA) was used during rotary processes.

\subsubsection{Processing conditions}

The processing conditions were set as illustrated in Table 1. Before the start of a run, the load was conditioned to a uniform initial temperature of about $40^{\circ} \mathrm{C}$ such that temperatures of the different containers were within $\pm 0.1^{\circ} \mathrm{C}$ at the start of each heat penetration test.

The weight of the sealed container before and after processing was always recorded.

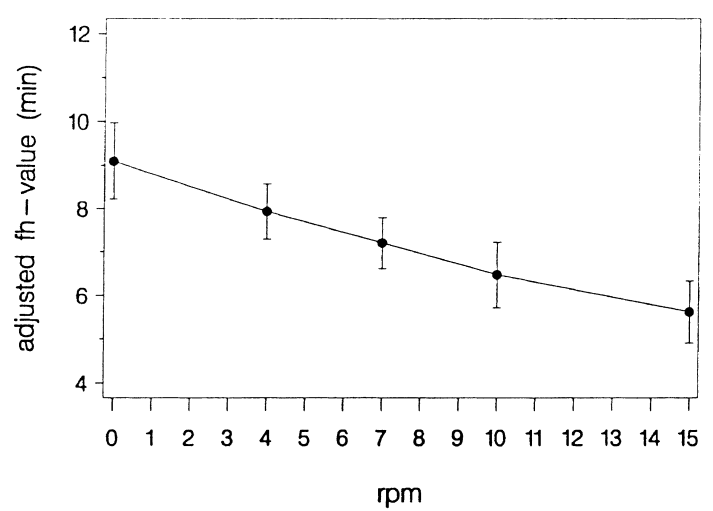

Fig. 2. Mean adjusted $f_{\mathrm{h}}$-values with standard deviations for white beans lot $\mathrm{B}$ as a function of rotational speed. 

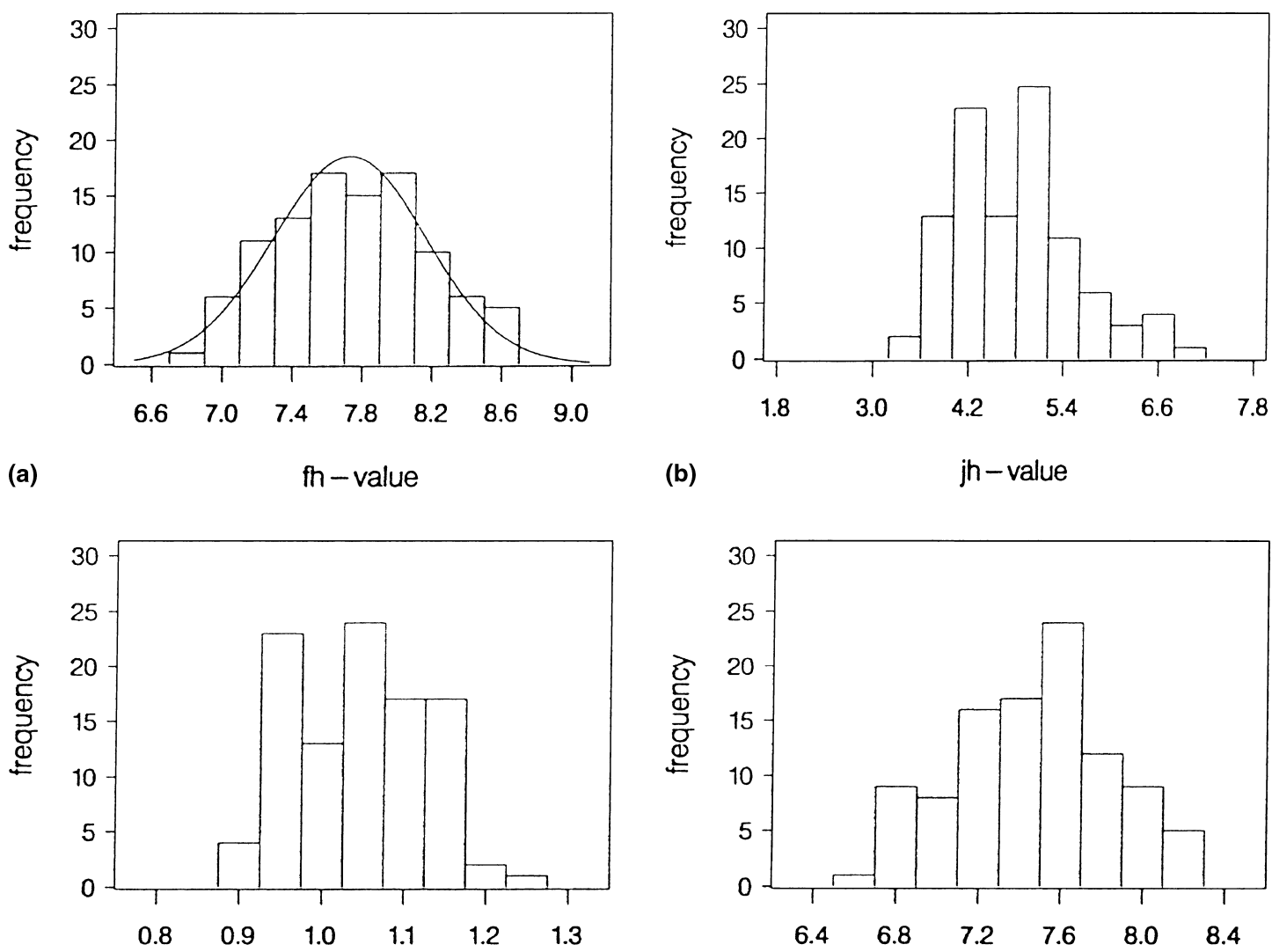

(c) jhb - value

(d)

adjusted fh-value

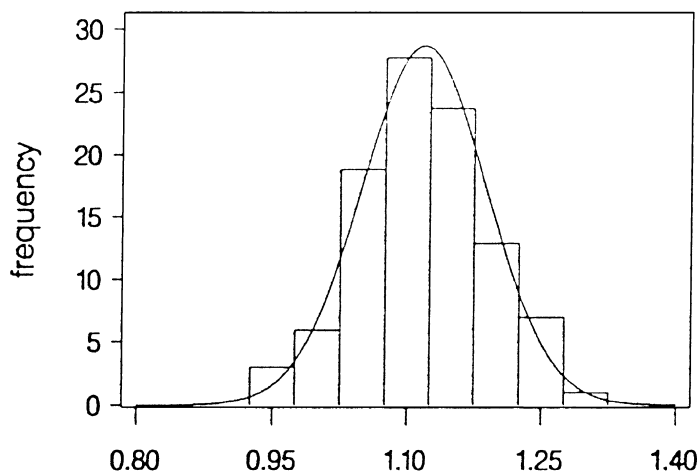

(e)

adjusted jh-value

Fig. 3. Distribution of the heating parameters of white beans lot $\mathrm{A}$ at $7 \mathrm{rpm}$.

\subsection{Non-uniformity in retort temperature}

Heat distribution was evaluated throughout a horizontal industrial-scale 4-basket rotary water cascading retort (Barriquand Steriflow retort, France) and indicated a uniform heat transfer from the heating medium to the containers throughout the retort (Smout, Van Loey \& Hendrickx, 1998). This implies that in such cases, an assessment of the heat distribu- tion of the retort can be reduced to a temperature distribution test. Time-temperature data were collected by locating 20 thermocouples (Fig. 1) throughout the retort. The temperature distribution was determined at 0,4 and $7 \mathrm{rpm}$. It was noticed that rotation improved the temperature distribution throughout the retort (under the processing conditions tested). For details on the temperature distribution trials reference is made to Smout et al. (1998). 


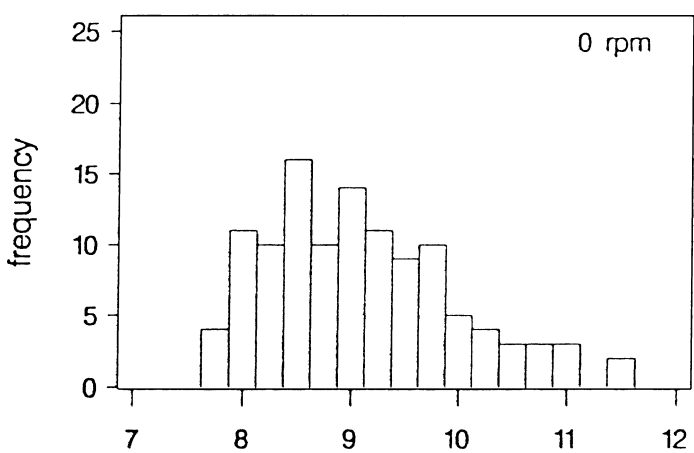

(a)

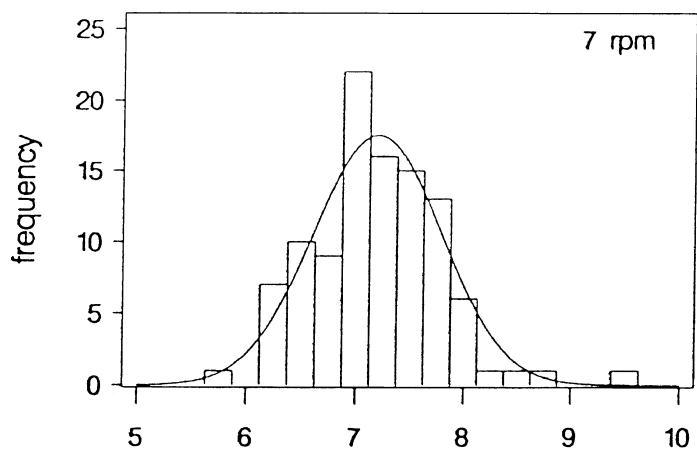

(c) adjusted $\mathrm{fh}$-value

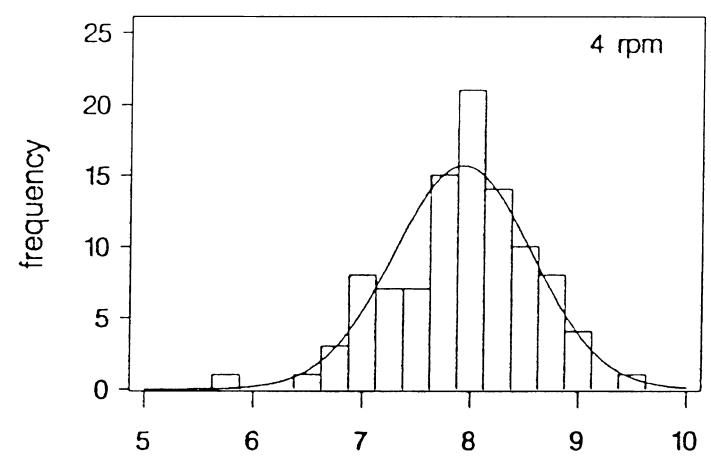

(b)

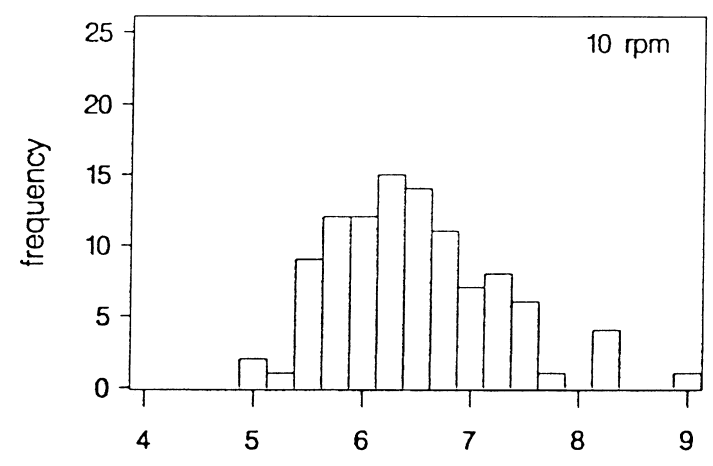

(d)

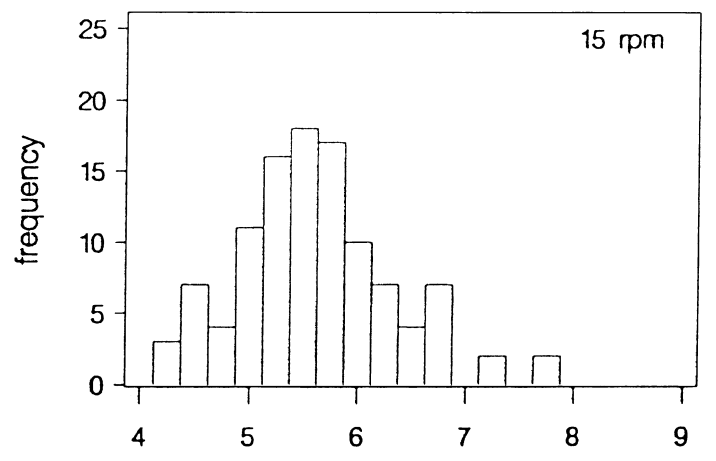

(e)

adjusted $\mathrm{fh}$-value

Fig. 4. Distribution of the adjusted $f_{\mathrm{h}}$-value of white beans lot $\mathrm{B}$ at different rotational speeds.

\subsection{Non-uniformity of lethality in retort processing}

A new approach to investigate non-uniformity of process lethality during in-pack thermal processing of foods was evolved (Smout, Van Loey \& Hendrickx, 2000). This approach consists of combining non-uniformity on retort level (heat distribution data) and non-uniformity on product level (heat penetration data) through simulations to investigate non-uniformity in lethality delivered to a given product processed in a given retort. From the mean and standard deviation of the heating parameters random adjusted $f_{\mathrm{h}}-j_{\mathrm{h}}$ combinations were generated (Monte Carlo simulation). A semi-empirical approach, the APNS (apparent position numerical solution) method (Noronha, Hendrickx, Van Loey \& Tobback, 1995), allows us to simulate, for each random $f_{\mathrm{h}}-j_{\mathrm{h}}$ combination, the time-temperature profile in the product during heating based on the time-temperature profile in the retort. The APNS-method enables to predict product temperature evolution when subjected to a variable heating medium temperature. From the time-temperature profile in the product, heating 
Table 3

Simulated mean $F_{0 \mathrm{~h}}$-values, standard deviation and range of $F_{0 \mathrm{~h}}$-values at different positions within an industrial-scale water cascading retort and, overall mean $F_{0 \mathrm{~h}}$-value, overall standard deviation and overall range of $F_{0 \mathrm{~h}}$-values for white beans lot A at 0 and $7 \mathrm{rpm}$

\begin{tabular}{|c|c|c|c|c|c|c|c|}
\hline \multicolumn{4}{|l|}{$0 \mathrm{rpm}$} & \multicolumn{4}{|l|}{$7 \mathrm{rpm}$} \\
\hline \multirow[t]{2}{*}{ Position } & \multicolumn{3}{|c|}{$F_{0 \mathrm{~h}}$-value } & \multirow[t]{2}{*}{ Position } & \multicolumn{3}{|c|}{$F_{0 \mathrm{~h}}$-value } \\
\hline & Mean & Standard deviation & Range & & Mean & Standard deviation & Range \\
\hline 1 & 1.86 & 0.34 & 1.42 & 1 & 5.46 & 0.72 & 3.28 \\
\hline 2 & 3.73 & 0.61 & 2.52 & 2 & 3.72 & 0.54 & 2.45 \\
\hline 3 & 4.78 & 0.72 & 3.00 & 3 & 5.59 & 0.73 & 3.35 \\
\hline 4 & 5.00 & 0.75 & 3.12 & 4 & 5.30 & 0.70 & 3.20 \\
\hline 5 & 3.91 & 0.64 & 2.65 & 5 & 4.55 & 0.63 & 2.85 \\
\hline 6 & 3.93 & 0.64 & 2.65 & 6 & 6.57 & 0.84 & 3.85 \\
\hline 7 & 5.00 & 0.77 & 3.20 & 7 & 5.71 & 0.75 & 3.45 \\
\hline 8 & 5.12 & 0.78 & 3.25 & 8 & 6.70 & 0.85 & 3.88 \\
\hline 9 & 5.05 & 0.76 & 3.18 & 9 & 6.69 & 0.84 & 3.87 \\
\hline 10 & 4.36 & 0.70 & 2.92 & 10 & 5.71 & 0.76 & 3.46 \\
\hline 11 & 3.66 & 0.60 & 2.51 & 11 & 5.86 & 0.76 & 3.50 \\
\hline 12 & 4.77 & 0.74 & 3.08 & 12 & 5.22 & 0.71 & 3.22 \\
\hline 13 & 5.04 & 0.76 & 3.19 & 13 & 6.41 & 0.82 & 3.76 \\
\hline 14 & 5.09 & 0.78 & 3.23 & 14 & 6.65 & 0.84 & 3.87 \\
\hline 15 & 5.36 & 0.80 & 3.35 & 15 & 5.18 & 0.70 & 3.21 \\
\hline 16 & 3.89 & 0.63 & 2.63 & 16 & 6.48 & 0.86 & 3.98 \\
\hline 17 & 4.87 & 0.74 & 3.09 & 17 & 6.15 & 0.80 & 3.68 \\
\hline 18 & 4.65 & 0.71 & 2.95 & 18 & 6.90 & 0.87 & 4.00 \\
\hline 19 & 5.27 & 0.78 & 3.27 & 19 & 6.69 & 0.84 & 3.87 \\
\hline 20 & 5.44 & 0.81 & 3.37 & 20 & 6.16 & 0.81 & 3.70 \\
\hline Overall & 4.54 & 1.09 & 6.18 & Overall & 5.90 & 1.12 & 6.29 \\
\hline
\end{tabular}

Table 4

Simulated ranges of $F_{0 \mathrm{~h}}$-values at different positions within the industrial-scale water cascading retort, overall range of $F_{0 \mathrm{~h}}$-values and coefficient of variation $(\mathrm{CV})$ of $F_{0 \mathrm{~h}}$-values

\begin{tabular}{llcc}
\hline & \multicolumn{2}{c}{$F_{\text {0h-values }}$} & \\
\cline { 2 - 4 } & Ranges & Overall range & CV (\%) \\
\hline White beans A 0 rpm & $1.42-3.37$ & 6.18 & 23.9 \\
White beans A 7 rpm & $2.45-4.00$ & 6.29 & 19.0 \\
White beans B 0 rpm & $4.18-8.00$ & 11.10 & 30.5 \\
White beans B 4 rpm & $4.20-6.69$ & 9.00 & 22.6 \\
White beans B 7 rpm & $4.00-5.98$ & 8.76 & 18.8 \\
\hline
\end{tabular}

lethalities $\left(F_{0 \mathrm{~h}}\right.$-values $)$ were calculated with the general method $\left(T_{\text {ref }}=121.1^{\circ} \mathrm{C}\right)$, using the kinetic parameters for Clostridium botulinum spore inactivation $\left(z_{\mathrm{m}}=\right.$ $\left.10^{\circ} \mathrm{C}\right)$

$F_{0 \mathrm{~h}}=\int 10^{\left(T-T_{\mathrm{ref}}\right) /\left(z_{\mathrm{m}}\right)} \mathrm{d} t$

First, the non-uniformity in lethality at each position within the retort was investigated, based on the 50 simulations at each position. Next, the non-uniformity in lethality throughout the retort was studied. For the simulation of white beans lot A and white beans lot B a holding time of 7 and $8 \mathrm{~min}$, respectively was applied in order to achieve process lethalities typical for white beans. The influence of rotation and process time on the non-uniformity of lethality throughout the retort was evaluated.

\section{Results and discussion}

\subsection{Statistical variability heat penetration parameters}

For each container, heating rate index ( $f_{\mathrm{h}}$-value), lag factor $\left(j_{\mathrm{h}}\right.$-value) and corrected lag factor according to Ball's $42 \%$ rule ( $j_{\mathrm{hB}}$-value) were calculated using the method of Ball (1923). Adjusted $f_{\mathrm{h}}$ - and $j_{\mathrm{h}}$-values were 
estimated using the APNS-method (Noronha et al., 1995). Adjusted heating parameters are independent of the boundary conditions (e.g. independent on the retort come up time). Estimates of means $(\bar{X})$ and standard deviations $(s)$, and coefficients of variation $(\mathrm{CV})$ of the heat penetration parameters are summarized in Table 2. Coefficients of variation of the heating parameters for white beans lot B were larger than for white beans lot A. The CV of the $j_{\mathrm{h}}$-values for white beans lot B were unexpectedly large. For white beans lot $\mathrm{A}$ at $7 \mathrm{rpm}$, the $\mathrm{CV}$ of the $j_{\mathrm{h}}$-value was also large. The variability was noticeably decreased when estimating the $j_{\mathrm{hB}}$-value and adjusted $j_{\mathrm{h}}$-value, where the actual come up time is taken into account. Although the pilot retort is able to perform reproducible processes with regard to come up time, the large CV of the $j_{\mathrm{h}}$-value should be linked to small variations in come up behavior of the retort.

Mean adjusted $f_{\mathrm{h}}$-values with standard deviation for white beans lot B were plotted as a function of rotational speed (Fig. 2). As expected, increasing rotational speed resulted in faster heat penetration (lower adjusted $f_{\mathrm{h}}$-values). The influence becomes much less pronounced as rotational speed exceeds $10 \mathrm{rpm}$. Increasing rotational speed over $10 \mathrm{rpm}$ results in more broken beans with leakage of starch, resulting in slower heat penetration. Van Loey et al. (1994) came to similar conclusions. For lot A the non-uniformity in heating characteristics was increased by rotation (larger coefficients of variation). For lot B, where a broader rotational speed range was studied, no clear relation between the non-uniformity of the heating parameters and the rotational speed was observed.

The test of normality, based on the Shapiro-Wilk statistic $W$, was calculated for the null hypothesis that the input data values are a random sample from a normal distribution (SAS, 1990). When ' $\operatorname{Pr}<W$ ' is smaller than 0.05 , the null hypothesis will be rejected at a $5 \%$ significance level.

As an example, the distributions of the heating parameters of white beans lot $\mathrm{A}$ at $7 \mathrm{rpm}$ are shown in histograms (Fig. 3). Theoretical normal distribution curves are added to the parameter distribution in case the null hypothesis, that the data constitute a random sample from a normal distribution, was not rejected. Fig. 4 shows the distributions of the adjusted $f_{\mathrm{h}}$-value of white beans lot $\mathrm{B}$ at the different rotational speeds. In literature, Herndon (1971) described the variability in heating rate index by a normal distribution, whereas Hayakawa, De Massaguer and Trout (1988) selected the gamma distribution to represent variation in $f_{\mathrm{h}}$ - and $j_{\mathrm{h}}$-values.

\subsection{Non-uniformity of lethality in retort processing}

First, the simulated mean $F_{0 \mathrm{~h}}$-value, the standard deviation and the range of $F_{0 \mathrm{~h}}$-values were analyzed for each position within the industrial-scale retort, based on the 50 simulations at each position. Next, the simulated overall mean $F_{0 \mathrm{~h}}$-value, the overall standard deviation and the overall range of $F_{0 \mathrm{~h}}$-values were calculated. As examples, the results of white beans lot $\mathrm{A}$ are shown in Table 3. Position numbers correspond to the numbers indicated in Fig. 1.

Inspection of the mean $F_{0 \mathrm{~h}}$-values at the different positions within the industrial-scale water cascading retort (Table 3) allows to conclude that the bottom of basket 1 (position 1) receives the lowest lethal effect in static mode, whereas the lowest process impact during rotary processes was observed at the center of basket 1 (position 2). A temperature distribution study also identified those positions as coldest zone (Smout et al., 1998).

\subsubsection{Influence of rotation}

The ranges of simulated $F_{0 \mathrm{~h}}$-values at different positions within the retort and the overall range of simulated $F_{0 \mathrm{~h}}$-values were analyzed and compared (Table 4). Agitation of white beans lot A slightly increased the overall range of $F_{0 \mathrm{~h}}$-values (i.e. absolute non-uniformity), but slightly decreased the coefficient of variation (i.e. relative non-uniformity). Rotation of white beans lot B decreased both the absolute and relative non-uniformity of lethality considerably. All this can be explained by a combined effect of: (i) an increased non-uniformity in heating characteristics by rotation for white beans lot A; (ii) no clear effect of rotation on the variability in heating parameters for white beans lot $\mathrm{B}$ and (iii) an improved temperature uniformity throughout the water cascading retort for rotary conditions compared to static conditions.

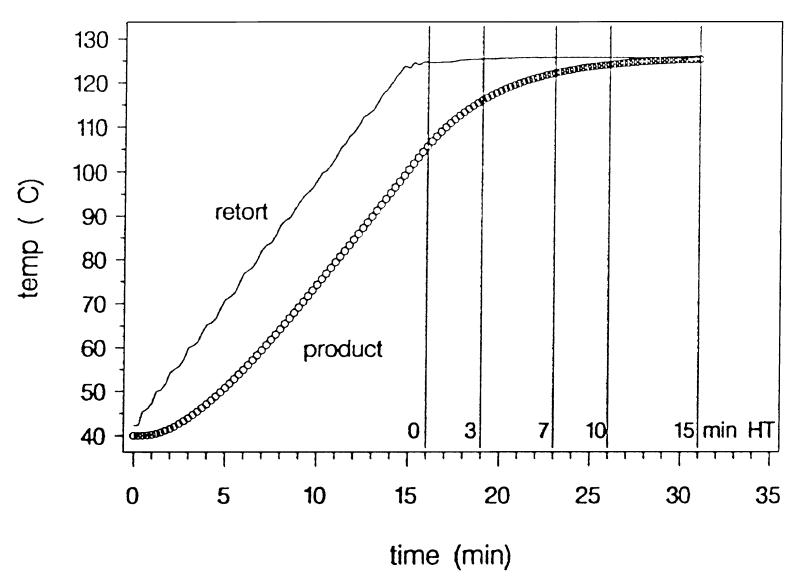

Fig. 5. Predicted product temperatures $(\circ \circ \circ)$ for white beans lot $A$ at $0 \mathrm{rpm}$ using an experimental retort temperature profile $(-)$ as boundary condition. 


\subsubsection{Influence of process time}

Propagation of the non-uniformity in lethality in the time domain is illustrated for white beans lot A (at 0 and $7 \mathrm{rpm}$ ) processed in the industrial-scale water cascading retort. Retort temperature profiles were cut off at $0,3,7$, 10 and 15 min holding time, as visualized in Fig. 5. The simulated non-uniformities in heating lethality are presented in Figs. 6 and 7. Results are summarized in Table 5.
Figs. 6 and 7 reveal that the shape of the frequency distribution is changed from positively skewed to negatively skewed as holding time is increased.

From Table 5 it can be concluded that the overall standard deviation and the overall range of $F_{0 \mathrm{~h}}$-values (i.e. absolute non-uniformity) are increased with increasing holding time, whereas the coefficient of variation (i.e. relative non-uniformity) is decreased as holding time increases.

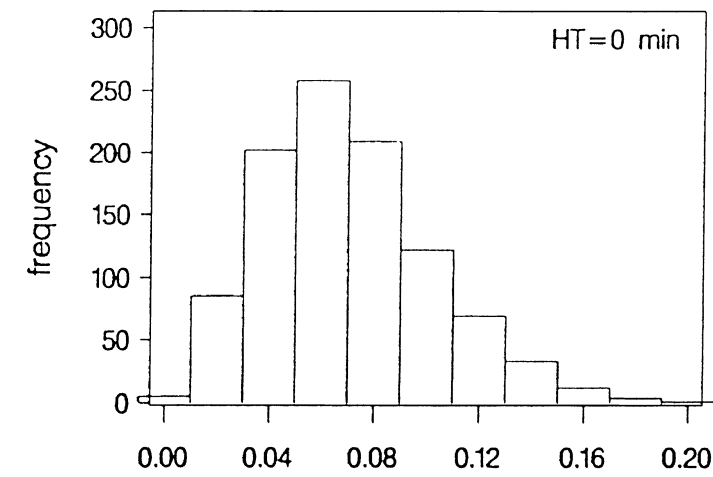

(a)

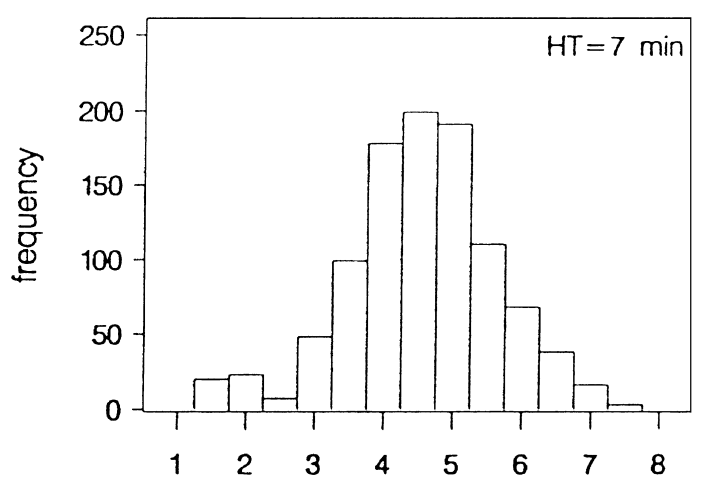

(c)
Foh

Foh

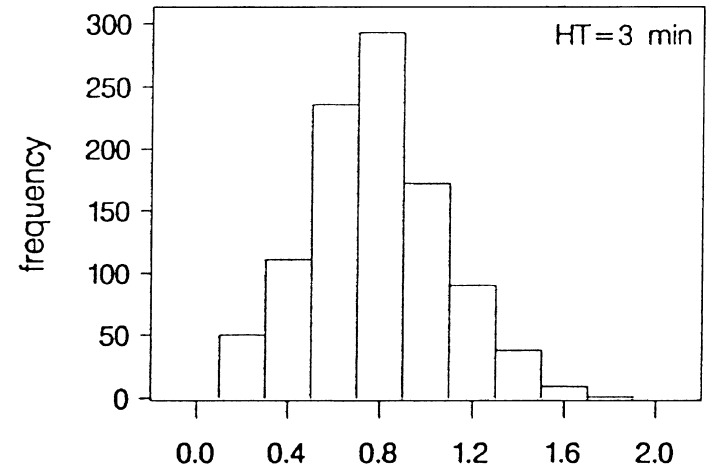

(b)

Foh

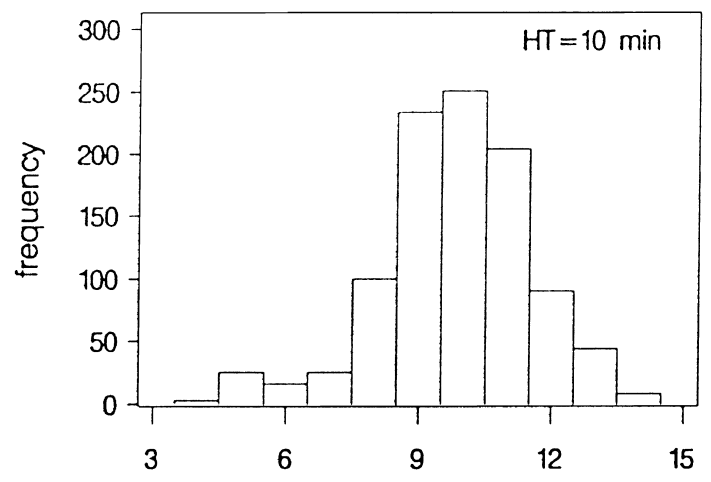

(d)

Foh

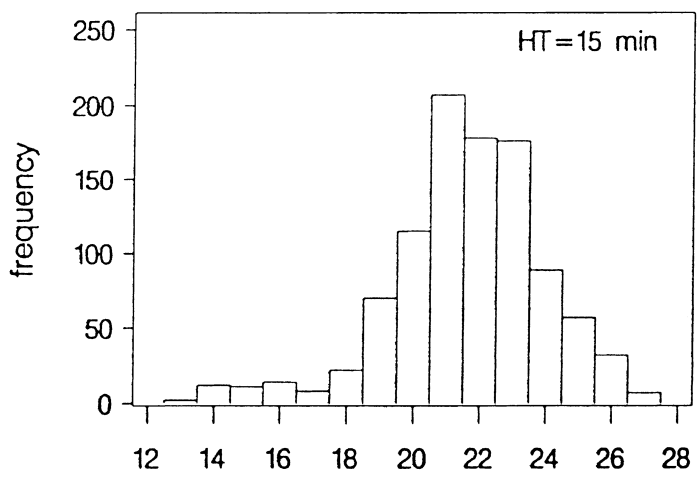

(e)

Foh

Fig. 6. Simulated non-uniformities in heating lethality $\left(F_{0 \mathrm{~h}}\right.$-value) throughout the industrial-scale water cascading retort for white beans lot A 0 rpm at different holding times. 


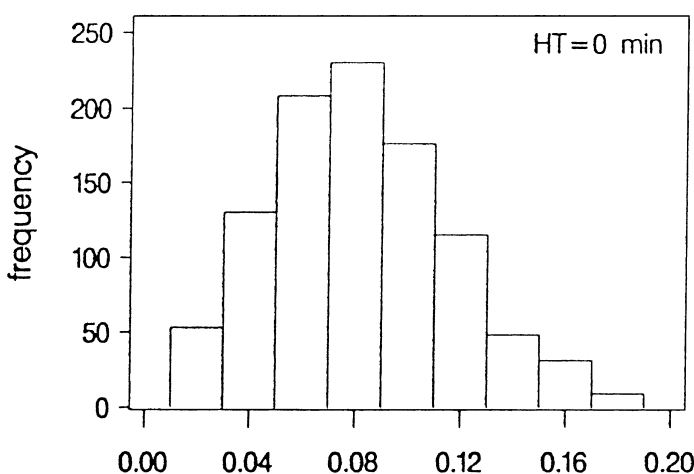

(a)

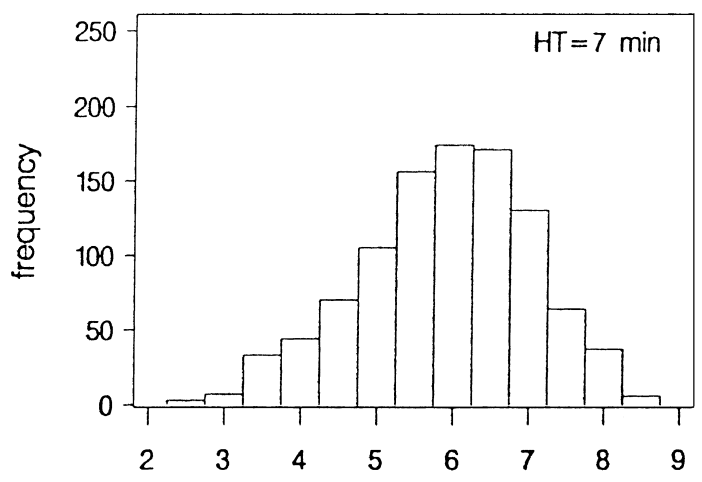

(c)

Foh

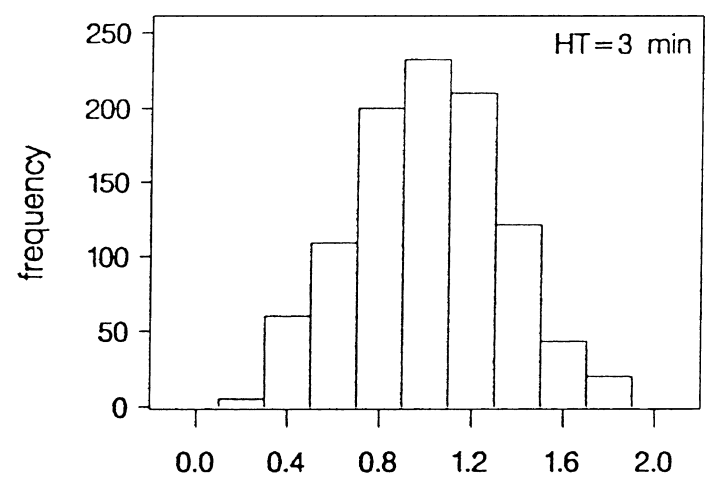

(b)

Foh

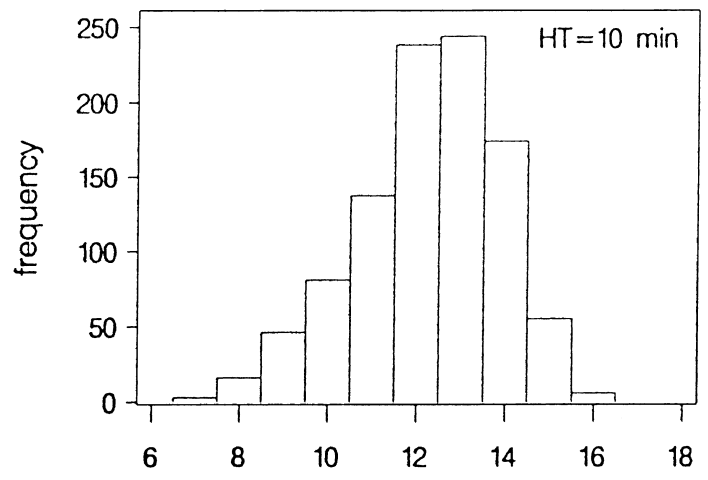

(d)

Foh

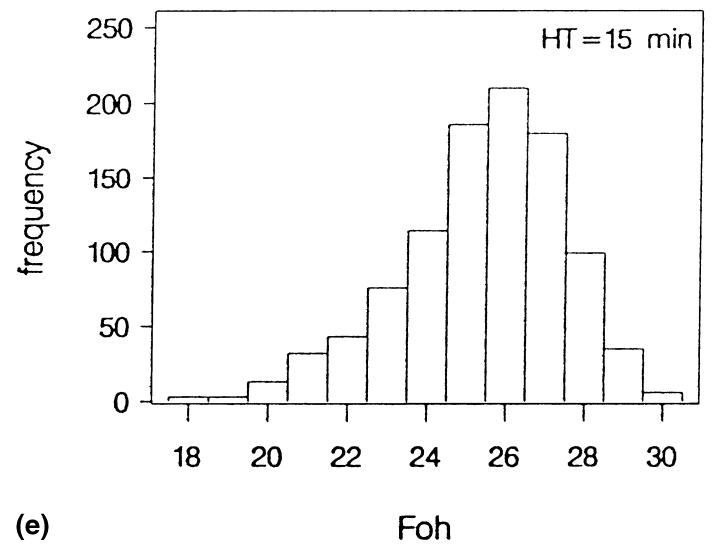

Fig. 7. Simulated non-uniformities in heating lethality $\left(F_{0 \mathrm{~h}}\right.$-value) throughout the industrial-scale water cascading retort for white beans lot $\mathrm{A} 7 \mathrm{rpm}$ at different holding times.

\section{Conclusions}

The lot-to-lot variability observed in this study proves that heat penetration parameters with their respective statistical variability should be determined for each lot of a product. The exact reason for the large variability of the heating parameters of white beans lot B was not clear. No distinct relation between the non-uniformity of the heating parameters and the rotational speed could be identified. Rotation seemed to influence process lethality variability throughout the retort through their influence on non-uniformity in heating characteristics and in retort temperature. Absolute non-uniformity (i.e. standard deviation) increased as holding time increases, whereas relative non-uniformity (i.e. coefficient of variation) decreased with increasing holding time.

\section{Acknowledgement}

We sincerely acknowledge the European Commission (Project AIR2-CT94-1017) for financial support. 
Table 5

Simulated overall mean $F_{0 \mathrm{~h}}$-value, overall standard deviation, overall range of $F_{0 \mathrm{~h}}$-values and overall coefficient of variation (CV) within the industrial-scale water cascading retort

\begin{tabular}{|c|c|c|c|c|c|}
\hline & \multirow[t]{2}{*}{$\mathrm{HT}(\min )$} & \multicolumn{4}{|c|}{$F_{\text {oh-values }}$} \\
\hline & & Mean & Standard deviation & Range & $\mathrm{CV}(\%)$ \\
\hline \multirow{5}{*}{$\begin{array}{l}\text { White beans lot A } \\
0 \mathrm{rpm}\end{array}$} & 0 & 0.065 & 0.033 & 0.19 & 51.0 \\
\hline & 3 & 0.77 & 0.29 & 1.61 & 37.7 \\
\hline & 7 & 4.54 & 1.09 & 6.18 & 23.9 \\
\hline & 10 & 9.82 & 1.69 & 9.90 & 17.2 \\
\hline & 15 & 21.63 & 2.32 & 13.95 & 10.7 \\
\hline \multirow{5}{*}{$\begin{array}{l}\text { White beans lot A } \\
7 \mathrm{rpm}\end{array}$} & 0 & 0.077 & 0.034 & 0.16 & 44.3 \\
\hline & 3 & 1.00 & 0.32 & 1.67 & 31.9 \\
\hline & 7 & 5.90 & 1.12 & 6.29 & 19.0 \\
\hline & 10 & 12.26 & 1.62 & 9.43 & 13.2 \\
\hline & 15 & 25.40 & 2.03 & 12.19 & 8.0 \\
\hline
\end{tabular}

\section{References}

Abbatemarco, C., \& Ramaswamy, H. S. (1993). Heating behavior and quality factor retention in a canned model food as influenced by thermal processing in a rotary retort. Journal of Food Quality, 16, 273-285.

Ball, C. O. (1923). Thermal process time for canned foods. Bulletin 37, vol. 7, Part 1. Washington, DC, USA: National Research Council.

Berry, M. R., Savage, R. A., \& Pflug, I. J. (1979). Heating characteristics of cream-style corn processed in a steritort: effects of headspace reel speed and consistency. Journal of Food Science, $44,831-835$.

Berry, M. R., \& Bradshaw, J. G. (1980). Heating characteristics of condensed cream of celery soup in a steritort: heat penetration and spore count reduction. Journal of Food Science, 45 (869-874), 879.

Berry, M. R., \& Dickerson, R. W. (1981). Heating characteristics of whole kernel corn processed in a steritort. Journal of Food Science, 46, 889-895.

Clifcorn, H. E., Peterson, A. T., Boyd, J. M., \& O’Neil, J. H. (1950). A new principle for agitating in processing of canned foods. Food Technology, 4, 450-457.

Hayakawa, K., De Massaguer, P., \& Trout, R. J. (1988). Statistical variability of thermal process lethality in conduction heating foodcomputerized simulation. Journal of Food Science, 53 (6), 18871893.

Herndon, D. H. (1971). Population distribution of heat rise curves as a significant variable in heat sterilization process calculations. Journal of Food Science, 36, 299-305.

Javier, R. A., Naveh, D., Perlstein, E., \& Kopelman, I. J. (1985). Convective heating rate parameters of model solutions in an agitating retort simulator. Lebensmittel-Wissenschaft und-Technologie, 18, 311-315.

Naveh, D., \& Kopelman, I. J. (1980). Effect of some processing parameters on the heat transfer coefficients in a rotating autoclave. Journal of Food Processing and Preservation, 4, 67-77.

Noronha, J., Hendrickx, M., Van Loey, A., \& Tobback, P. (1995). New semi-empirical approach to handle time-variable boundary conditions during sterilisation of non-conductive heating foods. Journal of Food Engineering, 24, 249-268.

Ramaswamy, H. S., Abbatemarco, C., \& Sablani, S. S. (1993). Heat transfer rates in a canned food model as influenced by processing in an end-over-end rotary steam/air retort. Journal of Food Processing and Preservation, 17, 269-286.

SAS Institute (1990). SAS Procedures Guide, Version 6 (3rd ed.). Cary, NC, USA: SAS Institute.

Smout, C., Van Loey, A., \& Hendrickx, M. (1998). Heat distribution study in an industrial-scale water cascading (rotary) retort. Journal of Food Science, 63 (5), 882-886.

Smout, C., Van Loey, A., \& Hendrickx, M. (2000). Non-uniformity of lethality in retort processes based on heat distribution and heat penetration data. Journal of Food Engineering (in press).

Tung, M. A., \& Britt, I. J. (1992). Heat transfer efficacy of overpressure media in rotational thermal processes for shelf stable foods in plastic packages. In R. P. Singh, \& M. A. Wirakartakusumah, Advances in food engineering (pp. 207-220). Boca Raton: CRC Press; London and Tokyo: Ann Arbor.

Van Loey, A., Francis, A., Hendrickx, M., Maesmans, G., Noronha, J., \& Tobback, P. (1994). Optimizing thermal process for canned white beans in water cascading retorts. Journal of Food Science, 59 (4), 828-832. 